\title{
Serious fun with computer games
}

\section{Sophisticated multimedia experiments offer platforms for learning about science through play, Aleks Krotoski finds.}

It is the year 2110, and the level of methane in the atmosphere has reached a critical threshold. You have a decision to make: accept the risk of global catastrophe and continue extracting the gas to meet the energy needs of an increasing population; implement a one-child-perhousehold rule to reduce future energy demand; or fund a decade-long research programme to deliver technological solutions.

These judgements on climate-change policy are central to Fate of the World, a computer game due for release in October. Through "a nail biting set of global warming scenarios", players will explore geoengineering, alternative energy sources and other options for protecting the planet over the next 200 years. By incorporating realistic predictions from climate models and advice from scientists, the game's developers, Red Redemption, hope to encourage players to engage with climate-change issues and to influence their attitudes and behaviours. Fate of the World is the latest commercial title in a growing library of computer games that seek to convey serious messages through play. But how effective are they?

Over the past decade, evidence has grown that computer-based play can support learning in schools. Pedagogical studies and evaluations, summarized in a 2006 joint report titled 'Unlimited Learning', by the UK government's education department and a software publishers' association, found that students whose lessons included interactive games were more engaged in curriculum content and demonstrated deeper understanding of concepts than those who did not use games. Better exam scores and teacher ratings resulted when computer games, both commercial and bespoke, were used as support materials. A plethora of organizations have sprung up to explore computerbased learning; in the United Kingdom, these include Futurelab in Bristol and the Serious Games Institute at Coventry University.

The success of computer games in engaging students lies in the mechanics of how they are designed. Jane McGonigal, a games researcher and designer at the Institute for the Future in Palo Alto, California, and Raph Koster, author of $A$ Theory of Fun for Game Design (Paraglyph, 2004), have each described several effective to engage in debates about evolution. charities. Attracting non-gamers is difficult: the word 'game' may alienate would-be players and devalue the serious messages within. As a result, some developers use alternative names for their products, such as 'behaviour-change platform?'

Broadening the appeal and effectiveness of educational games will require better products and targeted marketing. The playing experience must be immersive, coherent and believable. Games must not patronize or outpace systems in games that support learning. These include rewards, options that allow the user to navigate obstacles in a personalized way, opportunities to try out hypotheses and to fail in a safe space, iterative advance based on prior decisions and consecutive challenges that unfold logically. These rules echo many characteristics of scientific inquiry.

With good game mechanics, learning may result even when the educational material underlying the game has flaws. The 2008 game Spore, released by Electronic Arts, was criticized by educators for its unrealistic portrayal of evolution. Yet it was a critical and commercial success, proving that there is a market for mainstream games that tackle scientific theory. It encouraged the gaming community

The potential audience for such games is vast: two-thirds of US households play computer and video games, and one-third of UK residents consider themselves gamers. Yet few serious educational games make a profit - most rely on funding from government departments, media organizations and science-promoting

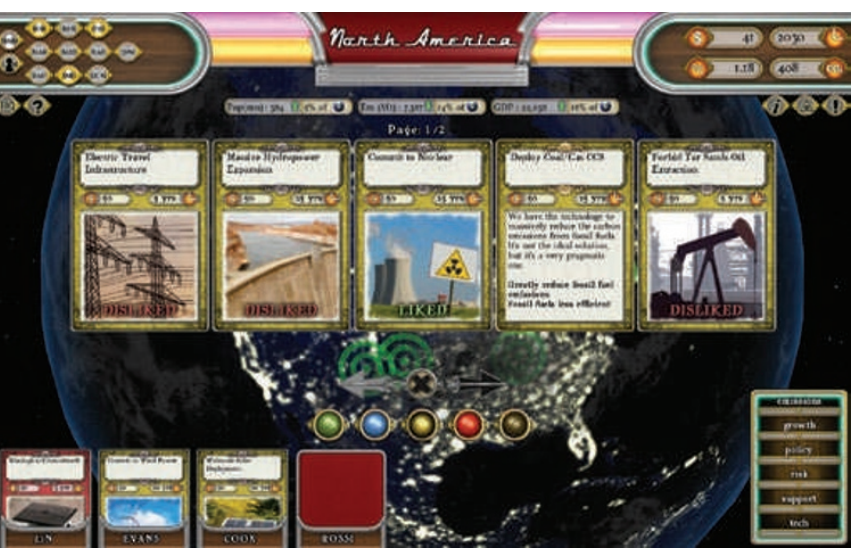

Interactive games such as Fate of the World foster learning by simulating climate-change decisions.

the participant. They should go beyond 'the dancing clown problem', in which students are dazzled by digitized versions of pop quizzes but don't retain knowledge.

An increasing number of computer games are achieving the desired balance. One example described as effective and fun by educators and those in the trade - is McGonigal's World Without Oil, co-designed and written by Ken Eklund. An interactive online experiment that ran over several weeks in 2007, it used realistic forecasts of our planet and asked people to collaborate on responses and descriptions of future life experiences that stemmed from their beliefs about fuel scarcity and energy shortage. Another is Red Redemption's 2007 PC game Climate Challenge, the proof-of-concept title preceding Fate of the World, into which research-based scenarios were also integrated. It attracted more than one million players.

Multiple media can enhance the mechanics of game playing. The alternate-reality games community keeps audiences enthralled outside a game's boundaries by sending players e-mails, instant messages and texts. They infiltrate the physical environment with city-wide billboard campaigns, live events and newspaper and magazine advertisements. They fabricate blogs, video diaries and websites to further increase users' sense of immersion.

This multimedia approach was used in Oil Productions' award-winning ROUTES, which explored genetics through videos, stories and traditional web games between January and March 2009. With more than 500,000 visitors and 4 million games played during the 3-month period it was live, and 675,000 viewers and 21 million players engaging with the website since, its successful formula has been used by its sponsors Channel 4 Education and the Wellcome Trust for other publicservice campaigns aimed at teenagers. These include $A d a$, an explorer puzzle game still in development but similar to Tomb Raider, that encourages girls to choose careers in science, and SuperMe, a game

released last month that seeks to boost young people's self-esteem.

Games provide an alternative platform for communicating science. If their mechanics are well designed, game play could help us to make better decisions about our future.

Aleks Krotoski is a researcher and journalist who specializes in the social applications of technology. She is currently Researcher in Residence at the British Library, London. e-mail: aleks@alekskrotoski.com 